$$
\log y=a \log e+b x \log e, \quad \text { Gewicht }=p_{1} .
$$

erhalten wir

$$
p_{1}=p M^{2}
$$

mit welchem Gewicht die Constanten dieser letzten Function, $a \log e$ und $b \log e$, berechnet werden missen.

Function

Ebenso .wenn in dem zweiten obigen Beispiel die

$$
y=\sin (a+b x), \text { Gewicht }=p,
$$

umgeformt wird in

$$
\operatorname{arc} \sin y=a+b x, \text { Gewicht }=p_{1} .
$$

erhalten wir

$$
\begin{gathered}
p_{1}=p\left(\mathrm{r}-M I^{2}\right) . \\
\& 5 .
\end{gathered}
$$

Wir setzen noch hinzu, dass nicht selten eine gegebene Function auf mehr als tine Art sich in eine lineäre Function umformen lässt, so dass man auswählen kann. Ein solcher Fall tritt z. B. ein, wenn man aus

ableitet
1) $y=a^{x}$,
Gewicht I

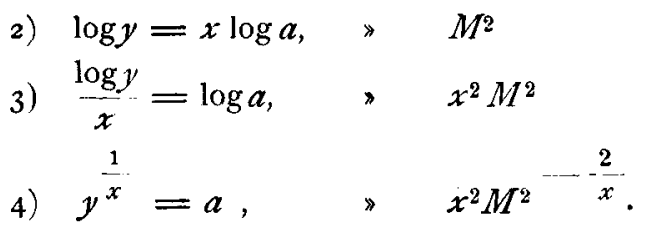

Wir haben ein numerisches Beispiel zur Bestimmung der unbekannten Constante $a$ nach allen diesen 4 Gleichungen, mit den hier beigesetzten Gewichten, durchgerechnet und die Arbeit in 2), 3) und 4) nahe gleich gross gefunden, während sie in r), wo der Weg der successiven Annäherung eingeschlagen werden musste, und wie wir hinzusetzen, mit Erfolg eingeschlagen werden konnte, ohne Vergleich grösser war. Das Endresultat der vier Rechnungen war genau dasselbe.

Hannover I 882 Juni.

\title{
On the Period of the Variable R Hydrae.
}

When considering this variable in the Uranometria Argentin a, pp. $300-302$, I showed that it was possible to represent, within reasonable limits, all existing observations of its maxima excepting Maraldi's, by means of a formula there given. This had been deduced upon the supposition of an error of one year in the date assigned for Maraldi's second maximum, which 1 assumed to be 1707 May 20 instead of I 708 May 20 ; and the accordance thus attained between the calculated epochs and the observed ones proved quite satisfactory. But at the same time I stated, that not having access to the original publication in the $\mathrm{M}$ émoires de Paris for 1709, no copy of which probably exists in all South America, it was impossible to know whether the supposition of such a misprint was tenable.

Visiting home during the autumn of 1880 , my attention was called by Mr. S. C. Chandler to the fact that the details given by Maraldi are totally incompatible with that supposition. This error was accordingly mentioned in the lists of Corrigenda in the Uranometry, published in No. 2377 of the Astr. Nachr., and in the second volume of the $*$ Results of the Cordoba Observatory «; and a new investigation was undertaken with such additional material as I had been able to collect.

This new investigation has been one of singular difficulty and labor, on account of a complication of embarrassing circumstances, and the need of numerous tentative processes for determining the number of periods elapsed in the intervals between the observed maxima. The observations of Hevelius and Montanari afford only approximate limits for the dates of the respective maxima; there is an uncertainty of two years as to Montanari's observation; and for nearly three quarters of a century, from Maraldi's observations to Pigott's, the star seems to have been utterly disregarded by astronomers. A single tolerably good determination between the years $I 7 \mathrm{I} I$ and $\mathrm{I} 7 \mathbf{8}_{4}$ would have made the problem comparatively easy, although the varying signs of the coefficients in the formulas when arranged according to powers of the time offer an additional difficulty.

Even now a certain amount of uncertainty remains, owing to the doubt regarding the year of Montanari's discovery. All the computations have therefore been made with equal care upon each of the two assumptions. Although I have myself but little doubt regarding the true year, the evidence is by no means thoroughly convincing and still less sufficiently unquestionable to make it needless to deduce the best results attainable upon each hypothesis. For this reason as well as others, it is important to consider minutely all the data at our disposal concerning the ancient observations.

r. Hevelius. Argelander cites the Machina Coelestis II $4 \mathrm{r} 3$, where are observations made 1662 Apr.I8, 19. The magnitude is not there given, although it is put down as 6 in Hevel's catalogue. Maraldi states (M ém. de Paris, 1706 p. r 17 ) that Hevel noted it as $5^{\mathrm{m}}$; but, as Argelander has pointed out, no evidence is to be found in favor of the assertion. Had the star been fainter than $6^{\mathrm{m}}$, it is improbable that Hevel would have seen it at all; and, had it been much brighter, his attention would probably have been specially attracted to it. We may therefore fairly assume, with Argelander, that it may have been 50 or 60 days from maximum at the time of these observations; and may regard all dates from February 22 to June $\mathbf{2} 2$ as about equally probable, in the absence of other information.

2. Montanari. I will quote Argelander's words, (Bonner Beobb. VII 34 I), correcting however a typographical error in his reference. 
This star was, as is well known, first announced as new by Montanari, inasmuch as Hevel's determination of it had not yet been published. He found it while comparing Bayer's Uranometry with the sky, when he perceived a star of the $4^{\text {th }}$ magnitude situated in the straight line passing trough $\psi$ and $\gamma$ Hydrae and as far distant from $\gamma$ easiwardly, as $\psi$ is, toward the west. But as to the year of this discovery there is some doubt. In two passages of the Mémoires de Paris (1706 Mém. p. II5 and I709 Hist. p. $8 I$ ), the date is given as April 1672 ; but, on the other hand, Maraldi gives in two other places (1 706 Mém. pp. I 16, I 17 and 1709 Mém. pp. $36-38$ ) the year 1670 as that of the discovery, and moreover always uses this in his calculations. This last-mentioned year is also cited by Cassini (Élémens d'Astronomie p. 75) and Lalande (Astronomie I p. $265 \$ 813$ ); so that there can hardly be any doubt about it. It is remarkable, to be sure, that Montanari himself should make no mention of the star in his little treatise »Sopra la sparizione d'alcune stelle ed altre novita celeste, In the copy for which I am indebted to Director v. Littrow, the titlepage is indeed missing; but arcording to Weidler and Lalande, it was published in 1672 ; and that it was published later than 1670 may also be inferred from sundry passages in it. We should therefore naturally expect some mention of our star if Montanari had already found it in 1670. An opportunity to refer to it, at least, was where he says on p. 7

,Ma non è pure constellazione nel Cielo, che d'ammirabili novità, e di frequenti mutazioni insieme non faccia pompa; ó sia con l'aggiunto di nuove stelle, ó con l'estinzione d'alcuna delle più antiche, ò del rinforzo di luce in alcune, $\partial$ con la diminuzione de gli splendore in altre. Andromeda, Perseo, l'Orse, il Drago e quasi tutte il Settentrione ne sono feracissimi." Why does not Montanari here name Hydra also? But to be sure the whole treatise is rather an academic speech, in very inflated style, than a sientific memoir « etc.

This argument in favor of the year 1672 appears to me more convincing than Argelander seems to have considered it; while that in favor of 1670 , from the fact that Cassini and Lalande cite this year, does not appear to me so strong. Maraldi had received his information through Bianchini at Rome, from manuscript notes left by Montanari; and the circumstance that he gives both 1670 and 1672 , as the year of discovery, in each of the two volumes of the Paris Memoirs makes the ambiguity as complete as possible. That Cassini and Lalande give the earlier date proves little; for Lalande would naturally follow Cassini, whose statement was apparently derived from Maraldi's account in the Mémoires für 1706 , whence he could have quoted either one year or the other. What strikes me as the most important point in favor of 1670 is that Maraldi used this date in his calculations, but these were neither very elaborate nor critical, and the argument seems greatly overbalanced by Montanari's ommission to allude to his own discovery of this remarkable star when discoursing within a year or two thereafter, upon the existence of variable stars, and citing sundry constellations in which they had been found.
The uncertainty in question is peculiarly unfortunate, because the star must have been very near its maximum on April I 5, if then really of the fourth magnitude. In such case an error of more than ten days would be very unlikely. In case any not improbable formula could be found, which should satisfy other observations within reasonable limits, and at the same time be compatible with a maximum in April of only one of these years, - this might be accepted as sufficient evidence that a maximum occurred within a very few days of April 15 in that year.

3. M araldi. Besides placing on record, in this ambiguous manner, the accounts of Montanari's discovery, Maraldi himself made the only observations from which we can deduce the record of any maximum during more than a century, until those which Pigott observed at York in I 784 and 1785 . Although Maraldi's observations are extremely crude, they are definite enough to afford some criterion as to the admissibility of any formula deduced from the modern observations. And we have here the two remarkable facts, that Cassini has given, in his Elémens d'Astronomie, sundry observations by Maraldi, of important bearing upon the dates of two maxima later than those regarding which he had himself published his results (although his communications to the Paris Academy continued until $\mathbf{I 7 2 3}$ ); and that Argelander, who cites Cassini's book, p. 75 relative to the maxima of 1704 and 1708 , should have omitted to mention the observations relative to those of 1709 and $17 \mathbf{1} 2$ which are printed upon the reverse of the same leaf.

The epochs which are deducible from the observations published by Maraldi himself are, as has been mentioned, totally incompatible with my supposition in the Uranometria Argentina, that the second of his maxima had in fact occurred in the year 1707 . He states, namely, as follows:

The star was invisible, even with the telescope, in April 1702 .

Two years later, at the beginning of March I $7 \mathrm{C} 4$, it was of the $4^{\text {th }}$ magnitude, being brighter than $\psi \mathrm{Hy}$ drae. It continued of about the same brilliancy until the beginning of April, after which it slowly diminished until it disappeared to the naked eye about the end of May, although remaining visible with the telescope for a month longer.

Toward the close of November 1705, it was barely visible for the naked eye. It was in diminution, and became lost to the I 2 -foot telescope at the end of $\mathrm{Fe}$ bruary 1706.

It was not seen again until I $708 \mathrm{Apr}$. I 8, at which date it was brighter than the $\sigma^{\text {th }}$ magnitude; although a month earlier it had been looked for in vain. On Apr. 24 it had increased, yet was not so bright as $\psi \mathrm{Hy}$ drae; but it was equal to this star on May II, and brighter on May 16 and 20. On June 5 it had slightly 
diminished, being then about equal to $\psi$, as it had been at the beginning of May.

The light of the star $\psi$ Hydrae, as seen without optical aid, is formed by that of $\psi$ itself and that of the star Ll. 24390, which precedes it by $\mathbf{2 2}^{\mathrm{s}}$ and is less than I' south. Our Cordoba estimates make the former star $6^{\mathrm{m}}$, the latter $7 \frac{1 / 2}{2}$, and their combined light $5^{\mathrm{m}} 3$. If their magnitudes were the same in 1708 , the variable might have been markedly brighter than $\psi$, without attaining the fourth magnitude.

Maraldi himself gives no more observations; but in Cassini's Élémens d'Astronomie, p. 76, we find the foregoing data repeated, together with the following additional remarks, which Argelander does not cite:

"Le 23 Novembre 1709 elle reparût de nouveau, de la même grandeur que l'antepenultième de l'Hydre $[\psi]$. Elle était le 6 Décembre égale à celle qui en est proche, laquelle n'est visible qu'à la lunette. Le 7 Février elle était si petite qu'on avoit de la peine à la voir par la lunette.

Le 24 Mai de l'année I 7 I2, cette Étoile reparût pour la cinquième fois; elle était un peu plus petite que l'antepenultième de l'Hydre. On la jugea le 9 Juin égale à l'Étoile informe, qui lui est proche, et on ne laissa pas de la distinguer aisément, nonobstant le clair de la Lune. Elle parût un peu plus petite le 16 Juin, et se perdit enfin de vue. «

Without entering into minute details of reasoning, founded upon the form of the light-curve near its maximum, we may infer from Maraldi's statements that maxima occurred

I) not far from I 704 March I;

2) not far from 1705 August $r$;

3) not far from 1708 June $I$.

And from Cassini's statements we may infer that others took place

4) a little previous to 1709 Nov. 23 , for which we will assume Nov, I8;

5) about the close of April I 7 I 2, for which we will assume April 30 .

Between the first and second of these epochs there was an interval of 17 months; between the second and third, an interval of 34 months, corresponding to a double period, - the intermediate maximum having occurred about I 707 Jan. I, when the star was not in a position to be seen at Paris; between the third and fourth, one of 17 months; but between the fourth and fifth it would be 29 months. This last interval is so clearly irreconcileable with all the other observations, ancient and modern, that Argelander doubtless rejected it on this account, as being unworthy of attention. But I think that we have here really a demonstrable error of one year. And the supposition of a maximum near the end of April I 7 I I is borne out by all the computations, made under whatsoever hypothesis.

As to the dates of the maxima observed in later years, there is comparatively little uncertainty or ambiguity. The least definite are those observed by Olbers in 1823 (Schumacher's Jahrbuch $184 \mathrm{I}$ p. ro4), and by Schwerd in 1827 (V. J. S. Astr. Gesellsch. V. I I 2 ). Olbers fixes the epoch as April 18, but his observations seem to indicate a somewhat later date, for which I assume April 23. Schwerd's epoch was deudced by Schönfeld, from the manuscript observations.

If Montanari's maximum took place in 1670 , eight periods must then have elapsed since Hevel's observation; and 26 more must have passed before Maraldi's of 1 704, thus making 34 between Hevel and Maraldi. But if it was in 1672 , then nine periods had passed since Hevel's, and 24 more were completed before Maraldi's; so that between Hevel and Maraldi there were only 33 periods. The number of periods included in the several intervals between the other observed epochs I believe to be at last establi. shed beyond room for reasonable doubt. But the uncertainty as to the date of maximum in 1662 is sufficiently great to permit the attainment of tolerably accordant results upon either supposition regarding Montanari's year. I have therefore deduced the best formula which I could obtain, upon each hypothesis independently, assuming that the several epochs of maxima could be represented by an expression of the form

$$
A+B n+C n^{2}+D n^{3}+E n^{4}+F n^{5}
$$

in which $n$ denotes the number of periods elapsed since a given epoch. As has already been stated the difficulty in determining the number of periods has been extreme and the values have in several instances been attainable only by slow and tedious processes of tentation. It has nevertheless proved feasible at last to obtain, upon each hypothesis, numerical values for the coefficients which afford an entirely satisfactory accordance with the observations. In fact the intrinsic probability of the two hypotheses, as deduced from the degree of their accordance, differs by a scarcely perceptible amount; so that the investigation throws no light upon the question of Montanari's year. Its only important result has been the determination of the number of periods comprised in the interval of 73 years between Maraldi's last and Pigott's first observation. That the expressions in this form do not represent the true law of the variation, is manifest from the fact that, for sufficiently large values of $n$, they would give negative values for the length of the period in the past as well as in the future.

But adopting the number of periods which they agree in indicating for the several intervals, cyclical expressions can be deduced which give a yet better accordance with observation. But even thus we obtain upon each hypothesis a series of residuals which may fairly be regarded as satisfactory. Still there seem to be marked indications in favor of the hypothesis $B$, which is that Montanari's observation was made in 1672 , the later of the two years in question. These indications, moreover, are strongly corroborated by the form of the goniometric expressions, which show a much better convergence of the coefficients deduced therefrom.

Upon Hypothesis $A$, or the supposition that Montanari's observation took place in 1670 , we find for the mean value of the period 368.30 days, and for the cycle 384 periods. The lenght of any period is given in days by the 
expression

$P_{n}=368.30+114.12 \sin n \varphi+46.2 \times \sin 2 n \varphi+36.50 \sin 3 n \varphi$ $+8.66 \sin 4 n \varphi+7.88 \sin 5 n \varphi+2.8 \mathrm{r} \sin 6 n \varphi$

where $n$ denotes the number of periods elapsed since the maximum of 1666 , or the $4^{\text {th }}$ after Hevelius, and $\varphi$ is the $384^{\text {th }}$ part of the circumference, or 15 sixteenths of a degree. Upon Hypothesis $B$, or the supposition that Montanari's observation occurred in 1672 , the mean value of the period becomes nearly twelve days longer, and the cycle contains 390 periods. We have then for the number of days in the $n^{\text {th }}$ period
$P_{n}=379.98+130.31 \sin n \varphi+44.80 \sin 2 n \varphi+30.03 \sin 3 n \varphi$ $+6.18 \sin 4 n \varphi+3.82 \sin 5 n \varphi+1.93 \sin 6 n \varphi$

in which $n$ is counted from the maximum of 1662 , being that of Hevelius, from which our epochs are counted in the accompanying table, and $\varphi$ denotes the $390^{\text {th }}$ part of a circumference, or 12 thirteenths of a degree.

The appended table contains the observed epochs of maximum, and those which result from the formulas, above given, for each hypothesis. The number of days is counted from 1875 , and the epochs are numbered from that of Hevel's observation.

\begin{tabular}{|c|c|c|c|c|c|c|c|c|c|c|}
\hline \multirow{2}{*}{\multicolumn{3}{|c|}{ Recorded maxima }} & \multicolumn{8}{|c|}{ Calculated Maxima } \\
\hline & & & \multicolumn{3}{|c|}{ Hypothesis $A$} & \multicolumn{5}{|c|}{ Hypothesis $B$} \\
\hline Observer & Date & Days from 1875.0 & Ep. & Date & Obs.-C: & Ep. & Date & & Obs.-C & \\
\hline Hevelius & I 662 April I 8 & -77687 & $\circ$ & Febr. 27 & $+50^{d}$ & $\circ$ & May & 2 & $-\mathbf{I}$ & 14 \\
\hline Montanari & I670 April I 5 & 74768 & 8 & April 15 & 0 & - & & & & \\
\hline & 1672 April I 5 & $74 \circ 37$ & - & & & 9 & April $\mathbf{I}$ & I 4 & + & \\
\hline Maraldi & I 704 Mar. I? & 62396 & 34 & Febr. 14 & +16 & 33 & Febr. 1 & 17 & +1 & 3 \\
\hline & I 705 Aug. I ? & 61878 & 35 & July 22 & +10 & 34 & July 2 & 23 & + & \\
\hline & 1708 June I? & 60843 & 37 & June 6 & - 5 & $3^{6}$ & Jnne & 6 & 一 & 5 \\
\hline & 1709 Nov. 18 & 60309 & $3^{8}$ & Nov. I 9 & --- & 37 & Nov, 1 & I 6 & + & \\
\hline & I 7 I April 30 & 59779 & 39 & May 2 & - & $3^{8}$ & April 2 & 26 & + & 4 \\
\hline Pigott & I 784 Jan. $\quad 26$ & 33211 & 90 & Jan. 25 & + & 89 & Jan. & 24 & + & 2 \\
\hline & 1785 May 25 & 32726 & 91 & June 3 & - & 90 & June & 2 & - & 8 \\
\hline Piazzi & I 805 May 5 & 25442 & 106 & May 8 & - & 105 & May & $\mathbf{I}$ & + & \\
\hline & I809 April 4 & 24012 & 109 & Mar. 3 I & + & 108 & Mar. & 24 & + & \\
\hline Olbers & 1818 Mar. $3^{1}$ & 20729 & 116 & Mar. 28 & + & I I 5 & Mar. & $2 \mathrm{I}$ & $+\mathrm{r}$ & ro \\
\hline & I 823 April 23 & I 8880 & 120 & April 27 & -- & 199 & April & 22 & + & \\
\hline Schwerd & 1827 Jan. 30 & I 7502 & I 23 & Febr. 8 & $\cdots-9$ & I 22 & Febr. & 5 & - & \\
\hline Argelander & 1843 May 30 & I $53^{8}$ & $13^{6}$ & May 17 & +13 & I 35 & May & 23 & + & \\
\hline Argelander & I 848 April 23 & & & & & & & & & \\
\hline Schmidt & May 5 & $973^{6}$ & 140 & May & + & I 39 & May & 6 & - & \\
\hline Schmidt & 1853 Mar. 29 & & & & & & & & & \\
\hline Argelander & April 7 & $793^{8}$ & I 44 & April 4 & + & I 43 & April & IO & - & \\
\hline Winnecke & I 858 Febr. 19 & & & & & & & & & \\
\hline Argelander & 20 & & & & & & & & & \\
\hline Schmidt & 28 & $615^{\circ}$ & I 48 & Mar. $\quad 2$ & - & I 47 & Mar. & 6 & - & \\
\hline Schmidt & 1859 May 2 I & & & & & & MaY & & & \\
\hline Argelander & $\begin{array}{l}25 \\
26\end{array}$ & $5^{699}$ & 149 & May 23 & + & I 48 & May & 27 & 一 & \\
\hline Schmidt & I 863 Jan. I 9 & $43^{64}$ & $15^{2}$ & Jan. 20 & - & I 5 I & Jan. & 22 & - & \\
\hline & I 864 April I 4 & $39 \times 3$ & 153 & April 9 & +5 & 152 & April & Io & + & \\
\hline & I 865 July 4 & $34^{6} 7$ & I 54 & June 26 & + & I 53 & June & 27 & + & \\
\hline Schönfeld & I 869 Febr. 8 & 2152 & I 57 & Febr. ro & - & $15^{6}$ & Febr. & I I & 一 & \\
\hline & I 7 & 2161 & & & & & & & & \\
\hline Schönfeld & I870 April I 9 & & & & & & & & & \\
\hline Schmidt & 24 & I 712 & $15^{8}$ & April 25 & - & I 57 & April & 27 & - & \\
\hline Schmidt & 1871 July 3 & 1277 & I 59 & July 8 & - & $15^{8}$ & July & 9 & - & \\
\hline Schmidt & I 876 April I 2 & 468 & 163 & April 14 & 一 & 162 & April & I 5 & - & \\
\hline & 16 & & & & & & & & & \\
\hline Schmidt & 1877 June 23 & 905 & I 64 & June 20 & + & 163 & June & 2 I & + & \\
\hline
\end{tabular}

In these numerical computations I have been assisted by Dr. E. Gutermann, without whose valuable aid it would have been impossible for me to have secured the time requisite for the investigation. 
The length of a period at the time of Hevel's observation was $35^{8.6}$ days upon the hypothesis $A$ and 380 days upon hypothesis $B$, and it is the close approach of these periods to one year, when combined with the great uncertainty as to the date of that maximum, which gives rise to a large part of the difficulty found in deciding between these hypotheses. The results obtained cannot be said to discountenance either, yet the scale appears to me to turn in favor of the second, from whatever point of view the question be considered. The presumption from examination of the historical data, the greater convergence of the coefficients in the expression for the length of the period, and the decided, even though slight superiority of the accordance of the formula with the observations, all testify in favor of the hypothesis $B$.

An interval of ten years or more must elapse before the question can be fully decided. Until the year 1893 the epochs of maxima deduced from the two hypotheses agree closely. They differ for that year by only four days, or scarcely more than the probable error of their observation. But the difference after that time increases rapidly and amounts to ten days in 1897 . The epochs given by the two formulas for the next eighteen years are as follows:

Cordoba 1882 April 30.

\begin{tabular}{|c|c|c|c|c|}
\hline \multirow[b]{2}{*}{ Year } & \multicolumn{2}{|c|}{$A$} & \multicolumn{2}{|c|}{$\bar{B}$} \\
\hline & Epoch & Date & Epoch & Date \\
\hline I 882 & I 68 & Mar. & 167 & Mar. \\
\hline 1883 & 169 & May & I 68 & May \\
\hline 1884 & 170 & July & 169 & July \\
\hline r 885 & I $7 \mathrm{I}$ & Sept. 6 & 170 & Sept. 3 \\
\hline r886 & I 72 & Nov. $\quad 2$ & 171 & Oct. $3{ }^{\circ}$ \\
\hline I 887 & I 73 & Dec. 29 & 172 & Dec. 26 \\
\hline 1889 & I 74 & Febr. 19 & I 73 & Febr. I 7 \\
\hline 1890 & I 75 & April 14 & 174 & April I 2 \\
\hline 1891 & 176 & June $\quad 2$ & I 75 & June $\quad 2$ \\
\hline 1892 & I 77 & July 2 I & 176 & July 22 \\
\hline ז893 & 178 & Sept. 5 & 177 & Sept. 8 \\
\hline 1894 & I 79 & Oct. I 9 & 178 & Oct. 25 \\
\hline I 895 & $180^{\circ}$ & Dec. $\quad 2$ & 179 & Dec. 9 \\
\hline 189 & I 81 & Jan. II & 180 & Jan. 21 \\
\hline 1898 & 182 & Febr. 20 & 181 & Mar. 5 \\
\hline 1899 & 183 & Mar. 26 & 182 & April I 2 \\
\hline r 900 & I 84 & April 29 & 183 & May $2 \mathrm{I}$ \\
\hline
\end{tabular}

B. A. Gould.

\section{Maximum of $\mathrm{R}$ Hydrae.}

The recent maximum of $\mathrm{R}$ Hydrae was observed here by Messrs. J. M. Thome and C. W. Stevens; the former using a Zoellner photometer, and the latter estimating by means of the stars of the Uranometria.

Mr. Thome's observations began on March 4 somewhat too late, and continued until March 25, using $v$ and $\mu$ Centauri, $\pi$ Hydrae, $\iota$ Lupi and $\varphi$ Centauri for comparison. The best resultant curves give epochs for the maximum which vary between March 6 and March 9, according to the star employed as standard of reference; their mean indicating the $8^{\text {th }}$.

Cordoba 1882 April 30.
Mr. Stevens's series extended from Febr. 24 to April I3, and indicate a date between March 4 and 7. The magnitude attained was not far from $3 * 5$. On March 20 it had fallen to $3^{\mathrm{m}} 8$; on the $27^{\text {th }}$ to $4^{\mathrm{m}} \cdot \mathrm{O}$; on April 6 to $4 \cdot 5$; and on April 12 to $5 \cdot \frac{\mathrm{m}}{\mathrm{m}}$.

In each series the comparisons were embarassed by the employement of $\pi$ Hydrae, an orange-red star which appears to be at present some two or three tenths of a magnitude brighter than in 1873 , when the determinations for the Uranometry were made.

Beobachtungen des Cometen Wells, angestellt auf der Sternwarte in Arcetri.

\begin{tabular}{|c|c|c|c|c|c|c|c|c|}
\hline 1882 & M.Z. Arc. & $\Delta \alpha$ & $\Delta \delta$ & Vergl. & Ring & $\alpha$ app. & $\delta$ app. & * \\
\hline März 29 & I $\mathrm{I}^{\mathrm{h}} 23^{\mathrm{m}} 45^{\mathrm{s}}$ & 一 $\mathrm{O}^{\mathrm{m}} \mathrm{ro} \mathrm{O}^{\mathrm{s}} 286$ & +8.25 .5 & 7.0 & gr. $\mathrm{R}$. & $18^{\mathrm{h}} 12^{\mathrm{m}} \mathrm{I}^{\mathrm{s}} \mathrm{O}, 3$ & $+39^{\circ} \quad 6^{\prime} \times 0^{\prime \prime} \cdot 3$ & \\
\hline 29 & I I 43 10 & $\longrightarrow \quad 03.687$ & $+I 4.0$ & $3 \cdot 3$ & R. & $18 \quad 12 \quad 2.28$ & +39628.0 & $b$ \\
\hline $3^{\circ}$ & I I 35 & to 18.940 & to 33.3 & 5.4 & kl. R. & $\begin{array}{lll}18 & 13 & 59.95\end{array}$ & +394545.6 & $c$ \\
\hline 30 & I I $56 \quad 42$ & +254.534 & $-4 \quad 29 \cdot 3$ & 4.0 & gr. R. & $\begin{array}{lll}18 & 14 & 1.95\end{array}$ & +394629.2 & $d$ \\
\hline April 7 & io $45 \quad 12$ & $-2 \quad 15.9 \times 5$ & $\Longrightarrow 19.5$ & 4.4 & kl. R. & 1831 & +45 & $e$ \\
\hline Juli 10 & 91619 & $-1 \quad 3.275$ & +4.57 & 5.0 & kl. R. & $10 \quad 32 \quad 29.85$ & $+93^{2}$ & $f$ \\
\hline I I & 9840 & to 55.953 & to 8.8 & 4.4 & kl. R. & 10 3736.26 & +91737.9 & $g$ \\
\hline 13 & 53 & to 56.881 & - 54.6 & 4.4 & kl. R. & $10 \quad 47 \quad 14.54$ & $+849 \times 5.6$ & $h$ \\
\hline
\end{tabular}

